\title{
Adhesive Reattachment of Maxillary Right Central Incisor fragment: A Conservative Approach
}

\author{
Roopadevi Garlapati ${ }^{1}$, J ayaprada Reddy Surakanti², \\ Hari Kumar Vemisetty ${ }^{3}$, Ravi Chandra Polavarapu Venkata ${ }^{4}$
}

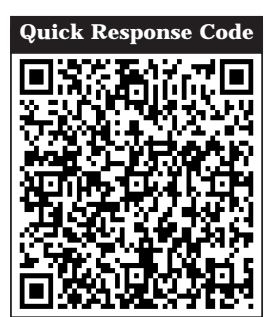

doi: $10.5866 / 2015.7 .10226$

'Senior Lecturer

2\&4Professor

${ }^{3}$ Professor and Head of Department

Department of Conservative Dentistry and

Endodontics,

Kamineni Institute of Dental Sciences,

Narketpally, India

\section{Article Info:}

Received: J uly 7, 2015

Review Completed: August 8, 2015

Accepted: September 9, 2015

Available Online: J uly, 2015 (www.nacd.in)

(c) NAD, 2015 - All rights reserved

\section{Email for correspondence:}

dr.rupagarlapati@gmail.com

\begin{abstract}
:
This case report presents the clinical case of coronal fracture of maxillary right central incisor involving enamel and dentin and the adhesive reattachment of tooth fragment. A twenty five year old male patient presented with coronal fracture of maxillary right central incisor. Followed by the reattachment of tooth fragment endodontic treatment was performed. Reattachment of fractured tooth fragment is an alternative restorative treatment where the tooth function and esthetics are immediately restored with conservation of tooth structure.
\end{abstract}

Key words: Coronal fracture, Dental trauma, Esthetics, Maxillary Central Incisor, Reattachment

\section{INTRODUCTION}

Maxillary anterior teeth are more prone for coronal crown fractures and mostly affect children and adolescents. Maxillary central incisors are mostly affected by dental injuries followed by mandibular central incisors whereas maxillary lateral incisors are less frequently involved. ${ }^{1,2}$ Coronal fractures of permanent incisors represent
$18-22 \%$ of all dental hard tissues trauma, of which 28-44\% are simple (involving enamel and dentin) and $11-15 \%$ are complex (involving enamel, dentin and pulp). Of these $96 \%$ of fractures involve maxillary central incisors. ${ }^{3}$ I mmediate attention is required for treating anterior teeth fracture as it may cause damage to the dentition of the young patient and also has psychological effect on children and their parents. ${ }^{4}$ 
Treating coronal fractures with or without pulpal exposure are challenging. Depending on the severity of fracture and its extent treatment is simple to complex restorative intervention. To maintain the exposed vital pulp a conservative treatment can be employed and endodontic treatment can be performed to sacrifice the pulp. ${ }^{5}$ First case report on reattachment of fractured incisor fragment was published by Chosack and Eildeman in $1964 .{ }^{6}$ Reattachment of the fractured fragment using acid-etch technique was first reported by Tennery. Starkey and Simonsen reported reattachment cases. ${ }^{7}$

With the developments and improvement in adhesive techniques and restorative materials, reattachment of patient's own tooth fragment to restore the fractured tooth is possible. With reattachment of tooth fragment better esthetics can be achieved, which helps in maintenance of wear resistance, less time consuming and has positive emotional and social response from the patient. ${ }^{4}$ The present case report presents the management of fractured maxillary right central incisor by reattachment of the same tooth fragment followed by endodontic treatment.

\section{CASE REPORT}

A twenty five year-old male patient reported to the Department of Conservative Dentistry and Endodontics with broken upper front tooth. His past dental history revealed that he underwent endodontic treatment for upper front tooth. On clinical examination, maxillary right central incisor showed complicated crown-root fracture extending from the center of the incisal edge going up to and beyond the cervical line subgingivally. The fracture was vertically in a labiopalatal direction without displacement of the fragment (Figure 1). As the fracture was incomplete, fractured fragment was mobile and the fragment was held in position palatally by soft tissue. A temporary restorative material was seen on the palatal aspect of maxillary right central incisor.

Radiographic examination reveal ed the fracture linein maxillary right central incisor extending from incisal edge through the pulp and extending into the cervical one third of the root. No associated root fracture was seen. Alveolar bone appeared normal. Periapical area showed a marginal rarefaction which was suggestive of inflammatory changes (Figure 2). Based on the above clinical and radiographic findings, maxillary right central incisor was diagnosed as complicated crown fracture (involving the pulp chamber) - Ellis Class III and chronic apical periodontitis. As thefracture was a complicated one, reattachment of fractured fragments followed by completion of endodontic treatment was planned and the patient was informed about the procedure.

The fractured fragment was detached from the main tooth structure by separating the gingival attachment using a No.15 BP blade (Figure 3). Debris was removed from the fractured fragment and then soaked in normal saline in order to prevent dehydration and discoloration of the tooth fragment and it was about $1-2 \mathrm{~mm}$ bel ow the cementoenamel junction.

The fractured fragment and the maxillary right central incisor werecleaned using pumice and water slurry. After isolation of the fractured tooth, acid etching of the fractured fragment surfaces and maxillary right central incisor surfaces was done with 37\% orthophosphoric acid (3M ESPE) for 15 seconds. Then the surfaces were rinsed thoroughly with water and air dried. The fractured fragment and the tooth were coated with Prime and Bond NT (Adper Single Bond, 3M ESPE) using applicator tip and cured for 20 seconds. On the buccal surface of maxillary right central incisor a $1 \mathrm{~mm}$ deep chamfer was prepared along the fracture line using a round bur (\#1016, KG Sorensen, Sao Paulo, Brazil). The fractured fragment was bonded to the remaining tooth structure of maxillary right central incisor using microhybrid composite (Filtek Z250, 3M ESPE) and subjected to visible light curing for 40 seconds per increment. Finishing and polishing of restored surfaces was done using Sof-Lex disks (3M ESPE) (Figure 4). Evaluation of occlusion and esthetics was done.

As the root canal treatment was incompletely done for maxillary right central incisor patient was recalled after 1 week for obturation of maxillary 


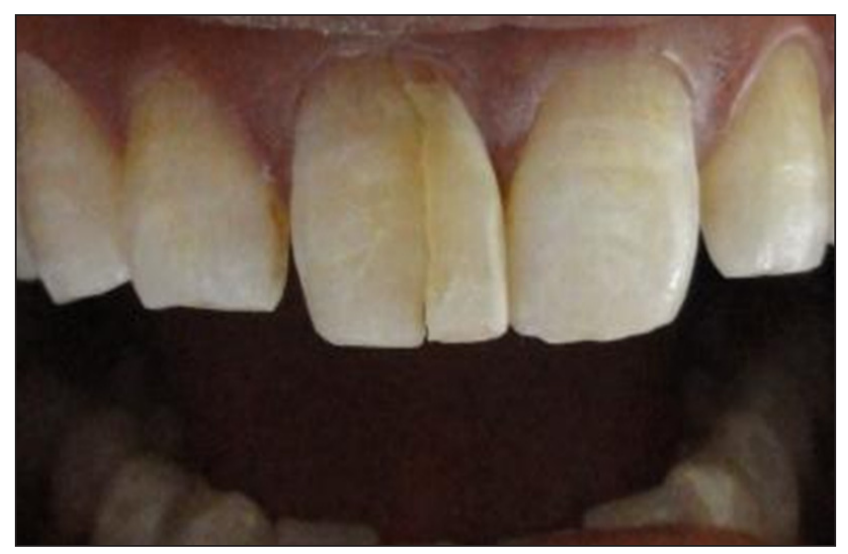

Figure 1: Pre-operative photograph of fractured maxillary right central incisor

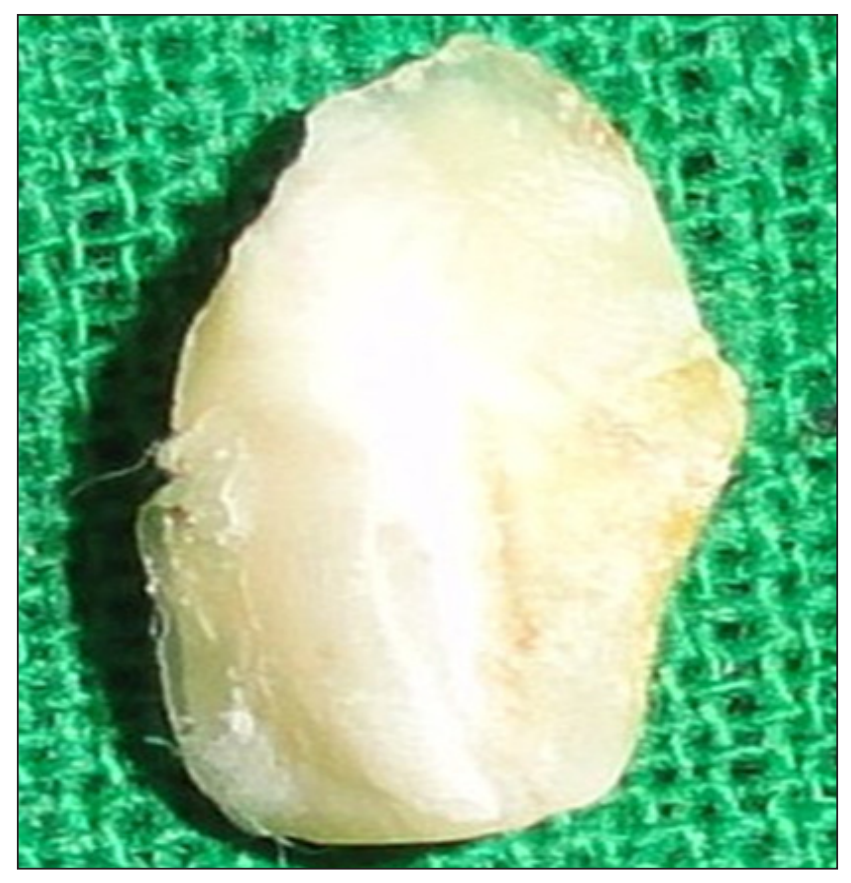

Figure 3: Detached fractured fragment

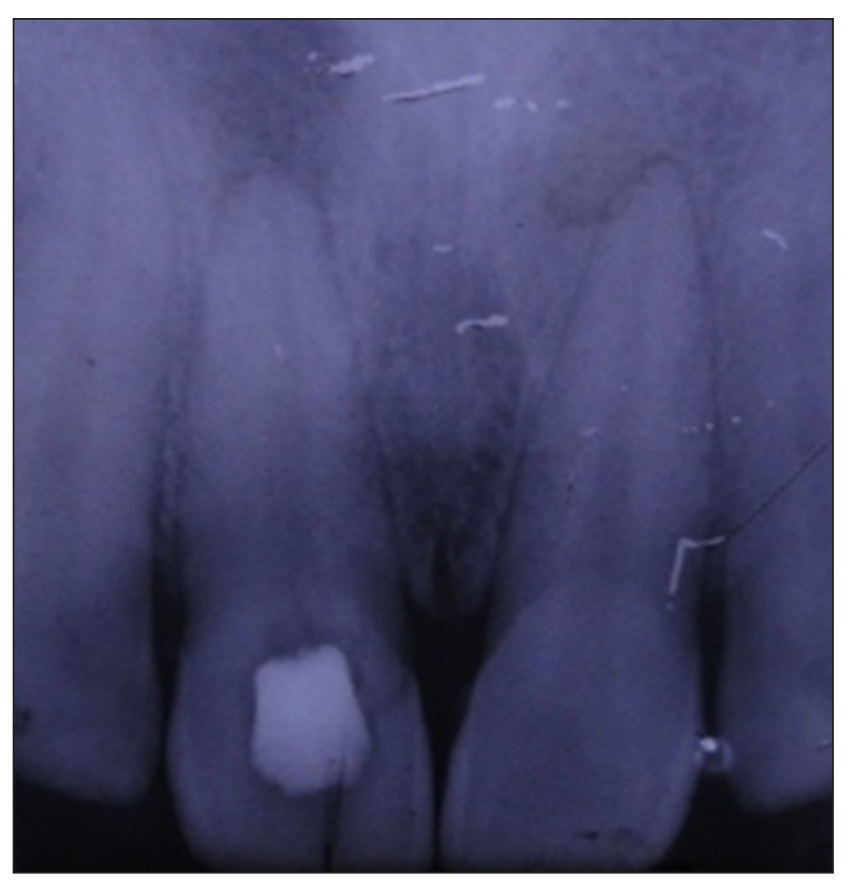

Figure 2: Pre-operative radiograph showing fracture.

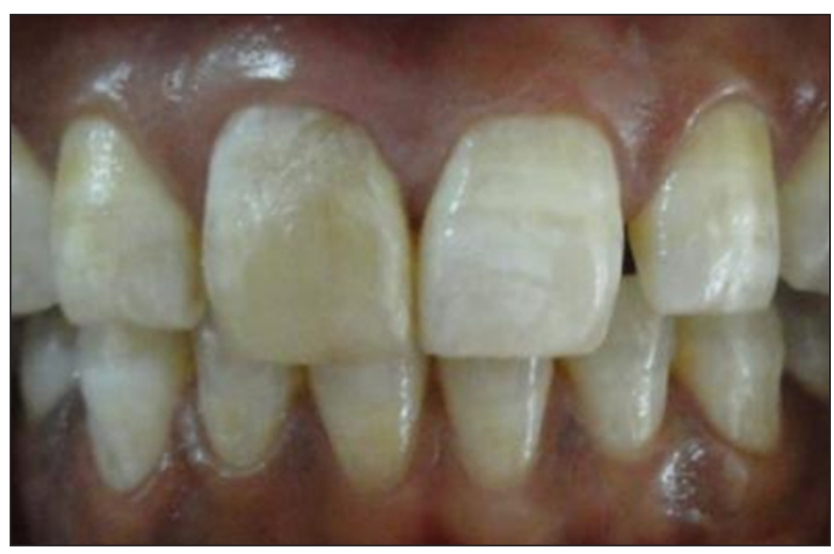

Figure 4: Post-operative photograph after fragment reattachment of maxillary right central incisor

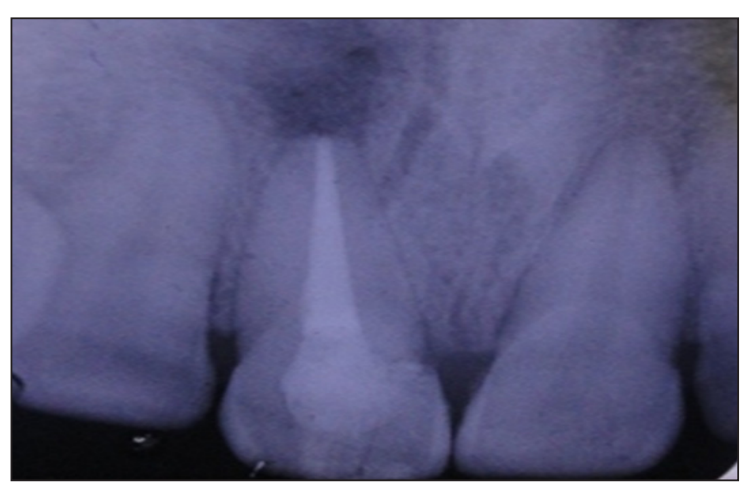

Figure 5: Post-obturation radiograph of maxillary right central incisor. 
right central incisor. At the second visit, temporary restorative material was removed, using apex locator working length was determined (Propex-II, Dentsplymallifer, Ballaigues, Switzerland) and confirmed by files in the radiograph. Cleaning and shaping was performed by hand instruments with step-back technique and instrumented upto master apical size of 60 ISO size K-file. Alternate irrigation was done by $3 \%$ sodium hypochlorite solution and saline. Root canal was dried with absorbent paper points and obturation was done by cold lateral compaction technique using zinc oxide eugenol as sealer. Root canal filling was found to be satisfactory from the post-obturation radiograph (Figure 5).The access cavity was restored with composite resin (Filtek Z250 3M ESPE). Patient was given postoperativeinstructions for preventing loading on the anterior teeth and was recalled for a visit after 1 month. Patient was asymptomatic, postoperative period was uneventful and the patient was satisfied with esthetics and function.

\section{DISCUSSION}

Fracture of anterior teeth is common among young children and teenagers. There is a positive emotional and social response from the patient in preserving the natural tooth structure. ${ }^{4}$ To restore the fractured teeth various techniques were employed which include pin retained restorations, stainless steel crowns, orthodontic bands, porcelain jacket crowns and complex ceramic restorations. ${ }^{8,9}$ These restorations requiretooth preparation, which were not esthetically adequate and cannot be employed in emergency esthetic situations. ${ }^{10}$

With the advancement of resin composites and adhesive systems, reattachment of tooth fragments has become a restorative technique with favourable prognosis rather than a provisional restoration. ${ }^{11}$ If the fractured fragment is available and intact, then reattachment of fractured segments is the most desired treatment. It restores tooth function, esthetics with a very conservative and cost effective approach and also close repositioning between fragments is available.

For reattachment of tooth fragment various techniques are employed, which include: ${ }^{12}$

\section{Placement of a circumferential bevel}

2. Placing an external chamfer, at the fractureline after bonding

3. Use of a V-shaped enamel notch

4. Placing an internal groove

5. In case of complicated fracture, superficial over contouring of the restorative material over the fracture line and pulp chamber.

Instead of a simple reattachment, in the present case enamel chamfer technique was employed, as it provided a better strength recovery. Reis et al. reported that with the chamfer technique better strength recovery can be obtained than simple reattachment. They suggested that with the chamfer technique $60 \%$ recovery of fracture strength can be obtained with minimal loss of natural fit of the fragment. When compared to other methods chamfer technique increased the strength recovery by exposing more resin surface to oral environment. Trope et al. reported that endodontically treated teeth can be reinforced by using resin composites. Flowable composites reinforces the tooth, helps in achieving high bond strength and also minimizes inclusion of voids. ${ }^{13}$

Reattachment of the fractured fragment offers many advantages. Reattachment of a fragment to the fractured tooth provides better esthetics, as the tooth's original form, color and surface texture are maintained. It restores function resulting in positive psychological response from the patient. It is most rapid and conservative treatment performed. ${ }^{14}$ The disadvantages with the reattachment are color changes of the fragment, less esthetic result if the tooth fragment is dehydrated, need of continuous monitoring and unknown longevity.

Reason for reattachment failures may be new trauma and/or parafunctional habits during night. To reduce the reattachment failures and to increase post treatment clinical success consideration must be given to patient education on treatment limitations and fabrication of a soft acrylic mouth guard. ${ }^{15}$ In the present case, rather than simple fragment reattachment additional preparation was performed for the reattachment of fractured 
fragment followed by endodontic treatment and also the fractured tooth fragment was intact. With the application of new generation adhesive systems long term and esthetic results can be achieved.

\section{CONCLUSION:}

The clinician should havea thorough knowledge of recent techniques availability, indications and proper planning of esthetic management of immediate traumatic injuries. When the available fractured tooth fragment is intact, reattachment of tooth fragment provides conservative, fast and esthetically pleasing result.

\section{REFERENCES}

1. Dietschi D, J acoby T, Dietschi J M, Schatz J P. Treatment of traumatic injuries in the front teeth: restorative aspects in crown fractures. Pract Periodontics Aesthet Dent 2000; 12:751-758.

2. Hamilton FA, Hill FJ, Holloway PJ. An investigation of dento-alveolar trauma and its treatment in an adolescent population. Part 1: The prevalence and incidence of injuries and the extent and adequacy of treatment received. Br Dent J 1997; 182:91-95.

3. Divakar HD, Nayak M, Shetty R. Changing concepts in fracture reattachment of teeth- A case series. Endodontology 2007; 2:27-35.

4. Hegede RJ . Tooth fragment reattachment - An esthetic alternative: Report of a case. J I ndian Soc Pedod Prev Dent 2003; 21:117-119.

5. Terry DA. Adhesive reattachment of a tooth fragment: The biological restoration. Pract Proced Aesthet Dent 2003; 15:403-409.
6. Reis A, Loguercio AD, Kraul A, Matson E. Reattachment of fractured teeth: A review of literature regarding techniques and materials. Oper Dent 2004; 29:226-233.

7. Simonsen RJ . Restoration of a fractured central incisor using original tooth fragment. J Am Dent Assoc 1982; 105:646-648.

8. Badami AA, Dunne SM, Scheer B. An in vitro investigation into the shear bond strengths of two dentine-bonding agents used in the reattachment of incisal edge fragments. Endodontics \& Dental Traumatology 1995; 11:129-135.

9. Buonocore MG and Davila J. Restoration of fractured anterior teeth with ultraviolet-light-polymerized bonding materials: a new technique. J Am Dent Assoc 1973; 86:13491354.

10. Goenka P, Dutta S, Marwah N. Biological approach for management of anterior tooth trauma: triple case report. J Indian Soc Pedod Prev Dent 2011; 29:180-186.

11. Simonsen RJ. Traumatic fracture restorations: an alternative use of the acid etch technique. Quintessence Int Dent Dig 1979; 10:15-22.

12. Reis A, Francci C, Loguercio AD, Carrilho MR, Rodrigues Filho LE. Re-attachmenof anterior fractured teeth: fracture strength using different techniques. Oper Dent 2001; 26:287-294.

13. L ondhe CSM, Garge BHG, Sudeep MS. Reattachment of Crown Fragment for I mmediate Esthetics. Medical J ournal Armed Forces India 2008; 64:387-388.

14. Maia EA, Baratieri LN, de Andrada MA, Monteiro S J r, de Araujo EM J r. Tooth fragment reattachment: fundamentals of the technique and two case reports. Quintessence Int 2003; 34:99-107.

15. Andreasen FM, Noren J G, Andreasen J O, Engel hardtsen $\mathrm{S}$, Lindh-Stromberg U. Long-term survival of fragment bonding in the treatment of fractured crowns: a multicenter clinical study. Quintessence Int 1995; 26:669-681.

\section{Gain quick access to our journal online View our journal at www.nacd.in}

